\title{
Diagnostic value of diffusion-weighted imaging (DWI) and diffusion tensor imaging (DTI) in differentiation between normal and abnormally thickened endometrium: prospective study
}

\author{
Mahmoud Abdel Latif* (D, M. Salah Tantawy and Hebatullah Safwat Mosaad
}

\begin{abstract}
Background: Diffusion tensor imaging (DTI) can be beneficial to differentiate between endometrium and other uterine layers. It is believed that it can be used to differentiate between normal and abnormally thickened endometrium. The purpose of this study was to find out the diagnostic value of DTI as an extension of DWI in characterization of abnormally thickened endometrium and differentiate it from normal.

Results: This study included 68 females, results of 3 of them were excluded (unable to complete the study), so the final number was 65 females subdivided into 2 groups; (A) control: 24 (13 premenopausal and 11 asymptomatic postmenopausal), (B) pathological thickened endometrium: 41 (11 premenopausal and 30 postmenopausal): benign (21 patients) and malignant (20 patients). The collected data was correlated to the histopathological results (as the gold standard) in cases of endometrial pathologies. The mean DW-ADC values for normal, benign, and malignant patients were $1.43 \pm 0.13,1.56 \pm 0.17$, and $0.86 \pm 0.16$ respectively and with significant statistical difference between normal and benign endometrial lesions ( $P$ value $=0.006$ ), and between normal and malignant endometrial lesions, and between benign and malignant endometrial lesions ( $P$ value $<0.001$ ).

The DTI-FA mean values for normal, benign, and malignant patients were $0.349 \pm 0.08,0.29 \pm 0.09$, and $0.299 \pm 0.08$ respectively and with significant statistical difference between normal and benign endometrial lesions ( $P$ value $=0.02)$, but there is no significant statistical difference regarding DTI-FA values between normal and malignant endometrial lesions or between benign and malignant endometrial lesions ( $P$ value $>0.05)$. Also, there is a significant statistical difference regarding DTI-MD mean values between normal (1.59 \pm 0.06$)$ and benign (1.37 \pm 0.09$)$, normal and malignant $(0.71 \pm 0.25)$, and between benign and malignant endometrial lesions ( $P$ value $<0.001)$. The DT-MD had a higher sensitivity, specificity, and accuracy than both DW-ADC and DT-FA in differentiating normal, benign, and malignant endometrial pathologies.
\end{abstract}

Conclusion: DTI (added to DWI) is a valuable non-invasive tool that can increase the accuracy in differentiating normal, benign, and malignant endometrial conditions, helping early management, and decrease the possibility of misdiagnosis.

Keywords: Endometrium, Diffusion tensor imaging, Diffusion-weighted imaging, Fractional anisotropy, Mean diffusivity

\footnotetext{
*Correspondence: drlatif72@yahoo.com

Mansoura University Hospital (MUH), Mansoura, Egypt
}

\section{Springer Open}

(c) The Author(s). 2021 Open Access This article is licensed under a Creative Commons Attribution 4.0 International License, which permits use, sharing, adaptation, distribution and reproduction in any medium or format, as long as you give appropriate credit to the original author(s) and the source, provide a link to the Creative Commons licence, and indicate if changes were made. The images or other third party material in this article are included in the article's Creative Commons licence, unless indicated otherwise in a credit line to the material. If material is not included in the article's Creative Commons licence and your intended use is not permitted by statutory regulation or exceeds the permitted use, you will need to obtain permission directly from the copyright holder. To view a copy of this licence, visit http://creativecommons.org/licenses/by/4.0/. 


\section{Background}

Radiologic evaluation of endometrial lesions may present many challenges to the radiologists. The normal endometrium has a dynamic structure, influenced by the patient's age, patient's menopausal status, stage in the menstrual cycle, and whether the patient receives hormonal replacement therapy or tamoxifen therapy [1]

A large spectrum of benign and malignant endometrial pathologies may involve the uterine cavity leading to abnormal appearance of the endometrium which may cause potentially overlapping imaging features of the normal endometrium and benign-malignant pathologies [2].

Endometrial cytology, biopsy, and curettage have been the mainstays for diagnosing lesions in the endometrial cavity. As these procedures are commonly performed blindly, they do not always provide a definitive diagnosis. Besides, they are difficult to perform in patients with vaginal or cervical stenosis and still considered invasive maneuvers [3].

Transvaginal ultrasonography (TVS) is considered the primary imaging modality for initial evaluation of suspected endometrial pathology but as the key sonographic findings may be nonspecific, overlap between the benign and malignant disorders, operator experience, and vaginal anomalies limit its usefulness [3, 4].

Conventional MRI is more sensitive than ultrasonography for the evaluation of uterine cavity lesions and provides excellent anatomical information of the uterus; however, the morphological appearance still may not differentiate some of the benign and malignant uterine lesions $[5,6]$.

In early stages of endometrial cancer (EC), the only imaging finding may be just endometrial thickening and no other imaging signs of malignancy (such as myometrial invasion), in these particular cases, overlapping may occur and some EC could be missed and diagnosed as a benign condition based on imaging [7].

Combination of diffusion-weighted imaging (DWI) to conventional MRI provide additional functional information which increased the accuracy in differentiating benign from malignant lesions; however, most of endometrial lesions either benign or malignant may cause high signal intensity in diffusion-weighted images similar to that of normal endometrium and this may cause a difficulty for reaching the accurate diagnosis [8].

Magnetic resonance diffusion tensor imaging (DTI) is an extension of DWI that can determine the directionality of water diffusion in great detail. DTI has been extensively used to study the microstructural architecture of normal and diseased brain. With the improvement in this technique in recent years, DTI is now applied to other areas of the body, such as skeletal muscles, prostate, breast, and kidney [9].
So DTI can be beneficial and complementary tool to differentiate between endometrium and other uterine layers and also can determine the intrinsic uterine fiber architecture. So, it is believed that it can be used to differentiate between normal and abnormally thickened endometrium either due to benign or malignant causes [10].

\section{Aim of the work}

The purpose of this study was to find out the diagnostic value of diffusion tensor imaging (DTI) as an extension of diffusion-weighted imaging (DWI) in detection, delineation, and characterization of abnormally thickened endometrium and differentiate it from normal, using fractional anisotropy (FA) and mean diffusivity (MD) mapping as a quantitative assessment tools.

\section{Methods}

At first, this study included 68 females, results of 3 of them were excluded as they were not able to complete the study, and so, the final number was 65 females.

Some patients were referred from the Gynecology and Obstetrics Department and others from the Oncology Center.

The study included adult females $\geq 18$ years old, participants who agreed to join the study according to the ethical considerations. All females participants were subdivided into 2 groups: Group A (control): 24 females (13 premenopausal females examined during the early proliferative phase of endometrial cycle as the endometrium thickness is the lowest, form $5-7 \mathrm{~mm}$ ) and (11 asymptomatic postmenopausal females). Inclusion criteria are healthy women with no history of gynecologic diseases or operation. Women using intrauterine contraceptive devices, taking oral contraceptives, or taking hormone replacement therapy were excluded because these are reported to affect uterine appearance on MR. Group $B$ (pathological or diseased): 41 females (11 premenopausal and 30 postmenopausal) patients presented by vaginal bleeding and abnormally thickened endometrium proved by transvaginal (TVS) examination. Also, all premenopausal females were symptomatic and examined in the early proliferative phase of the cycle to ensure that the thickened endometrium is pathological and not related to menstrual phases.

Virgins, pregnant women, females with general contraindication to MRI scanning, and patients underwent previous pelvic surgery or exposed to pelvic radio or chemotherapy were excluded in both groups.

The collected data was correlated to the histopathological results (as the gold standard) in cases of endometrial pathologies.

The examination was done at the Diagnostic Radiology Department (initial TVS examination in the ultrasound 
unit, and MRI examination in the MRI unit) in the duration from July 2018 to December 2019.

Written informed consents were taken from all participants.

All cases were examined by:

(1) Transvaginal ultrasound (TVS): The TVS examination was conducted on the commercially available Toshiba Xario using the transvaginal probe (661PVT-6 MHz).

(2) Magnetic resonance imaging (MRI): The MRI study was conducted on the commercially available 1.5 Tesla (Philips Ingenia) using Phased array coils.

(3) Histopathological examination of the abnormally thickened endometrium as a gold standard for correlation with MRI data.

\section{MRI protocol}

(A) Non-contrast conventional MRI sequences

- Axial T1WI (TR/TE, 400-600/10-14 ms); FOV, 32 $\mathrm{cm}$; matrix $263 \times 171$; slice thickness, $6 \mathrm{~mm}$; interslice gap, $1.3 \mathrm{~mm}$

- High-resolution sagittal and axial T2WI (TR/TE, 3000-6000/100-110 ms)

- T2WI with chemical shift-selective fat saturation pulse using the following parameters: (TR/TE, 40006000/100-120 ms); slice thickness, $5 \mathrm{~mm}$; gap, $1 \mathrm{~mm}$; field of view (FOV), 32 to $42 \mathrm{~cm}$; matrix, $256 \times 256$

(B) Diffusion-weighted imaging (DWI)

- DW-MRI in the axial, and sagittal planes using a single-shot echo-planar imaging sequence (TR/TE effective range, 8000-10,000/70-100; slice thickness/ intersection gap, 5/1 mm; FOV, 32 to $42 \mathrm{~cm}$; matrix, $128 \times 128$

- $b$ value 0,500 , and $1000 \mathrm{~s} / \mathrm{mm}^{2}$

- Generation of ADC maps for visual and quantitative analysis.

\section{(III)Diffusion tensor imaging (DTI)}

- Diffusion tensor, which consisted of a single-shot, medium or high (sensitivity encoding) SENSE, spin-echo echo-planar sequence in 16 encoding directions and a diffusion-weighting factor ( $b$ value) of 0 and $800 \mathrm{~s} / \mathrm{mm}^{2}$ in sagittal, axial or combined views using SS-EPI (slice thickness, $3 \mathrm{~mm}$; inter-slice gap, $1 \mathrm{~mm}$; repetition time (TR), 10,000 ms; echo time (TE),60 ms; matrix, $100 \times$ 132; voxel size, $1.67 \times 1.67 \times 3.00 \mathrm{~mm}$; acquisition time, $6.12 \mathrm{~min}$; number of excitations (NEX), 2; number of slices, 40.

- The field of view (FOV) was $320 \times 320 \mathrm{~mm}^{2}$, and the thickness and inter-slice gap values were the same for DTI and T2W images to enable anatomical compatibility for analysis.

\section{Post-processing (data analysis)}

The Digital Imaging and Communications in Medicine (DICOM) images were transferred to workstation (extended MR Workspace 2.6.3.5, Philips medical systems Nederland B.V) supplied by the vendor.

DW-ADC maps were generated from MRI-DW images.

DWI and DTI included qualitative and quantitative analysis:

(1) The qualitative analysis

Regarding the signal intensity, endometrial SI was evaluated on high $b$ value images, and corresponding DW-ADC maps.

Two dimensional (2D) analysis: DT-ADC (MD), DTFA gray-scale, and color-coded maps were automatically generated by the software. Visual assessment of the signal of the endometrium in those maps was done.

(2) The quantitative analysis

(a) DW-ADC maps

Single or multiple circular regions of interest (ROI) were drawn manually on the targeted regions.

(b) DTI maps

DT-FA and DT-ADC (MD) parameters were calculated by drawing elliptical, manually positioning region of interest (ROI). Five (5) ROIs were placed on the normal or diseased endometrium in the sagittal plane image and 3 ROIs in the axial plane image.

DT-FA was calculated as follows (Nott et al., 2017):

$$
F A \sqrt{\frac{3}{2} \cdot \frac{\left(\lambda_{1}-(\lambda)^{2}\right)+\left(\lambda_{2}-(\lambda)\right)^{2}+\left(\lambda_{3}-(\lambda)\right)^{2}}{\lambda_{1}{ }^{2}+\lambda_{2}{ }^{2}+\lambda_{3}{ }^{2}}}
$$

DT-ADC (MD) was calculated as follows (Nott et al., 2017): 


$$
\mathrm{MD}=(\lambda 1+\lambda 2+\lambda 3) / 3
$$

Mean values of DT-FA and DT-ADC (MD) of both sagittal and axial images were then calculated.

\section{Statistical analysis}

Data were fed to the computer and analyzed using IBM SPSS software package version 22.0. The normality of data was first tested with one-sample KolmogorovSmirnov test.

Descriptive (quantitative) data were calculated in the form of mean and standard deviation $( \pm S D)$.

Qualitative data were described using number and percent.

Validity was tested by sensitivity, specificity, positive predictive value (PPV), negative predictive value (NPV), and accuracy.

The used tests were one-way ANOVA test: for normally quantitative variables, to compare between more than two groups (normal and benign, normal and malignant, and benign and malignant).

For all previously mentioned statistical tests done, the threshold of significance is fixed at $5 \%$ level ( $P$ value). The smaller the $P$ value obtained, the more significant are the results.

\section{Results}

This study included 65 adult females; their ages ranged from 23 to 71 years with mean age 51.28 years $( \pm 12.15$ $\mathrm{SD})$.

The cases were divided into 2 main groups: (A) control normal 24 cases (13 premenopausal and 11 asymptomatic postmenopausal), with normal endometrial thickness and no abnormal signal intensity; (B) pathological thickened endometrium 41 (11 premenopausal and 30 postmenopausal): benign (21 patients) and malignant (20 patients) (Table 1 ).

There was a significant statistical difference between normal and malignant cases according to their ages $(P$ value $=0.01)($ Table 1$)$.
There was a significant statistical difference regarding endometrial thickness measured by TVS between normal and benign cases, as well as normal and malignant cases $(P$ value $<0.001)$, but there was no significant statistical difference between benign and malignant cases $(P$ value $=0.18)($ Table 1$)$.

The most common benign pathology among the studied cases was tamoxifen-induced hyperplasia (6 cases representing $28.6 \%$ of total benign cases), and the least common was endometrial adhesion ( 1 case representing $4.8 \%$ of total benign cases) (Table 2).

The most common malignant pathology among the studied cases was endometrioid adenocarcinoma grade 1 (about 8 cases representing $40 \%$ of total malignant cases), and the least common were clear cell carcinoma, and endometrial stromal sarcoma (each pathology 1 case representing 5\% of total malignant cases) (Table 2).

Regarding diffusion-weighted-apparent diffusion coefficient (DW-ADC) values, the mean value for normal (Figs. 1 and 2), benign (Figs. 3 and 4), and malignant (Figs. 5 and 6) patients was $1.43 \pm 0.13,1.56 \pm 0.17$, and $0.86 \pm 0.16$ respectively. There was a significant statistical difference between normal and benign endometrial lesions $(P$ value $=0.006)$, and also between normal and malignant endometrial lesions and between benign and malignant endometrial lesions $(P$ value $<0.001)$ (Table 3).

The diffusion tensor-fraction anisotropy (DTI-FA) mean values for normal (Figs. 1 and 2), benign (Figs. 3 and 4), and malignant (Figs. 5 and 6) patients were 0.349 $\pm 0.08,0.29 \pm 0.09$, and $0.299 \pm 0.08$ respectively. There was a significant statistical difference regarding DTI-FA values between normal and benign endometrial lesions ( $P$ value $=0.02)$, but there is no significant statistical difference regarding DTI-FA values between normal and malignant endometrial lesions or between benign and malignant endometrial lesions ( $P$ value $>0.05)$ (Table 3$)$.

For the diffusion tensor-mean diffusivity (DTI-MD) man values, there was a significant statistical difference between normal $(1.59 \pm 0.06)$ and benign $(1.37 \pm 0.09)$,

Table 1 Number of cases, age distribution, and endometrial thickness of the studied groups

\begin{tabular}{|c|c|c|c|c|c|}
\hline & $\begin{array}{l}\text { Normal } \\
\text { No. }=24 \\
(36.9 \%)\end{array}$ & $\begin{array}{l}\text { Benign } \\
\text { No. }=21 \\
(32.3 \%)\end{array}$ & $\begin{array}{l}\text { Malignant } \\
\text { No. }=20 \\
(30.8 \%)\end{array}$ & Test of significance & Within-group comparison \\
\hline Age/years & $47.28 \pm 14.15$ & $51.19 \pm 11.1$ & $56.15 \pm 8.33$ & $\begin{array}{l}F=3.07 \\
P=0.05\end{array}$ & $\begin{array}{l}\mathrm{P} 1=0.26 \\
\mathrm{P} 2=0.01^{*} \\
\mathrm{P} 3=0.18\end{array}$ \\
\hline Endometrial thickness by TVS (mm) & $5.96 \pm 1.64$ & $15.81 \pm 5.24$ & $16.3 \pm 3.25$ & $\begin{array}{l}F=50.82 \\
P<0.001^{*}\end{array}$ & $\begin{array}{l}\mathrm{P} 1<0.001^{*} \\
\mathrm{P} 2<0.001^{*} \\
\mathrm{P} 3=0.18\end{array}$ \\
\hline
\end{tabular}

F: One-way ANOVA test. P1: the difference between normal and benign lesions (P1 $<0.001^{*}$ as regards endometrial thickness). P2: the difference between normal and malignant lesions ( $\mathrm{P} 2<0.001^{*}$ as regards endometrial thickness). P3: the difference between benign and malignant lesions (P3 $=0.18$ as regard endometrial thickness). All parameters described as mean \pm SD 

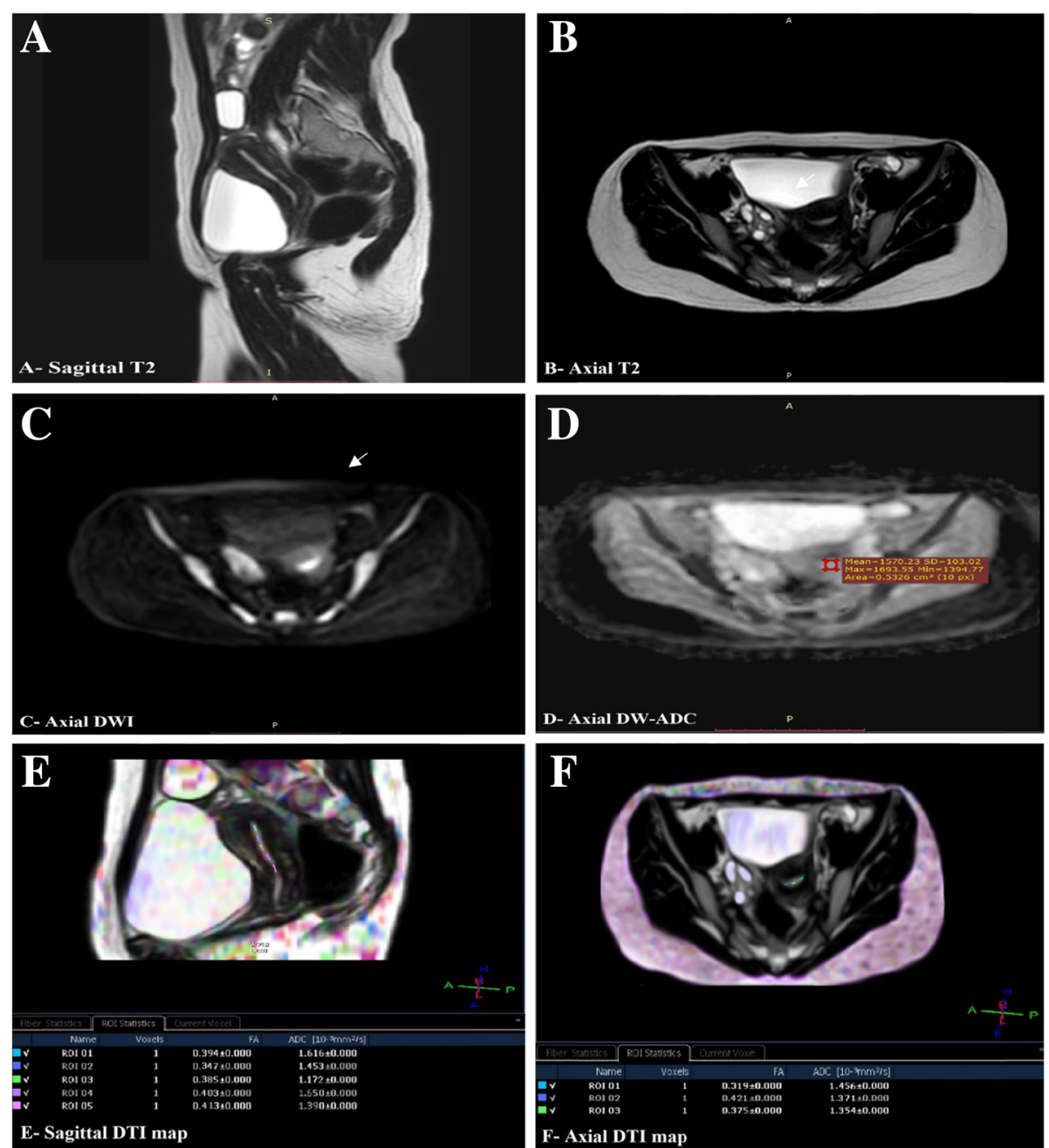

Fig. 1 A 24-year-old premenopausal female with endometrial thickness $6 \mathrm{~mm}$ by TVS. a, b Sagittal and axial T2Wls show normal zonal anatomy of the uterus. The central hyperintense stripe represents the endometrium (arrows); the band of low SI subjacent to the endometrial stripe represents the junctional zone (red stars). The outer myometrium is of intermediate SI (OM).c Axial DWI with $b$ value of $1000 \mathrm{~s} / \mathrm{mm}^{2}$ shows normal appearance of the endometrium with high signal intensity (arrow).d Axial DW-ADC map image shows normal appearance of the endometrium with intermediate signal intensity. Mean DW-ADC value $=1.570 \times 10^{-3} \mathrm{~mm}^{2} / \mathrm{s}$. e, f Sagittal and axial DTI map images demonstrate values of DT-FA and DT-ADC (MD) in multiple ROI along the endometrial stripe. Mean DT-FA value $=0.382$, and mean DT-MD value $=1.433 \times 10^{-3} \mathrm{~mm}^{2} / \mathrm{s}$. Diagnosis: normal endometrium

between normal and malignant $(0.71 \pm 0.25)$, and between benign and malignant endometrial lesions $(P$ value $\left.^{<} 0.001\right)$ (Table 3).

\section{For differentiation of benign and malignant endometrial lesions}

The receiver operating characteristic (ROC) curve for $D W-A D C$ using the cutoff point $\left(1.21 \times 10^{-3} \mathrm{~mm}^{2} / \mathrm{s}\right)$, yielded sensitivity, specificity, and accuracy of $89.5 \%$, 95.5\%, and $92.7 \%$ respectively (Table 4 ).

The ROC curve for DT-FA had a limited role with lower sensitivity, specificity, and accuracy (Table 4).
For the ROC curve for DT-MD, the sensitivity, specificity, and accuracy at the cutoff point $\left(1.03 \times 10^{-3} \mathrm{~mm}^{2} / \mathrm{s}\right)$ were $95.0 \%, 100.0 \%$, and $97.6 \%$ respectively (Table 4 ).

\section{For differentiation of normal and benign endometrial} lesions

The ROC curve for $D W-A D C$, using the cutoff point $\left(1.495 \times 10^{-3} \mathrm{~mm}^{2} / \mathrm{s}\right)$, had lower sensitivity, specificity, and accuracy of $61.9 \%, 58.3 \%$, and $60.0 \%$ respectively (Table 4).

Also, the ROC curve for DT-FA, at the cutoff point (0.342), had lower sensitivity, specificity, and accuracy of $76.2 \%, 52.0 \%$, and $58.7 \%$ respectively (Table 4 ). 

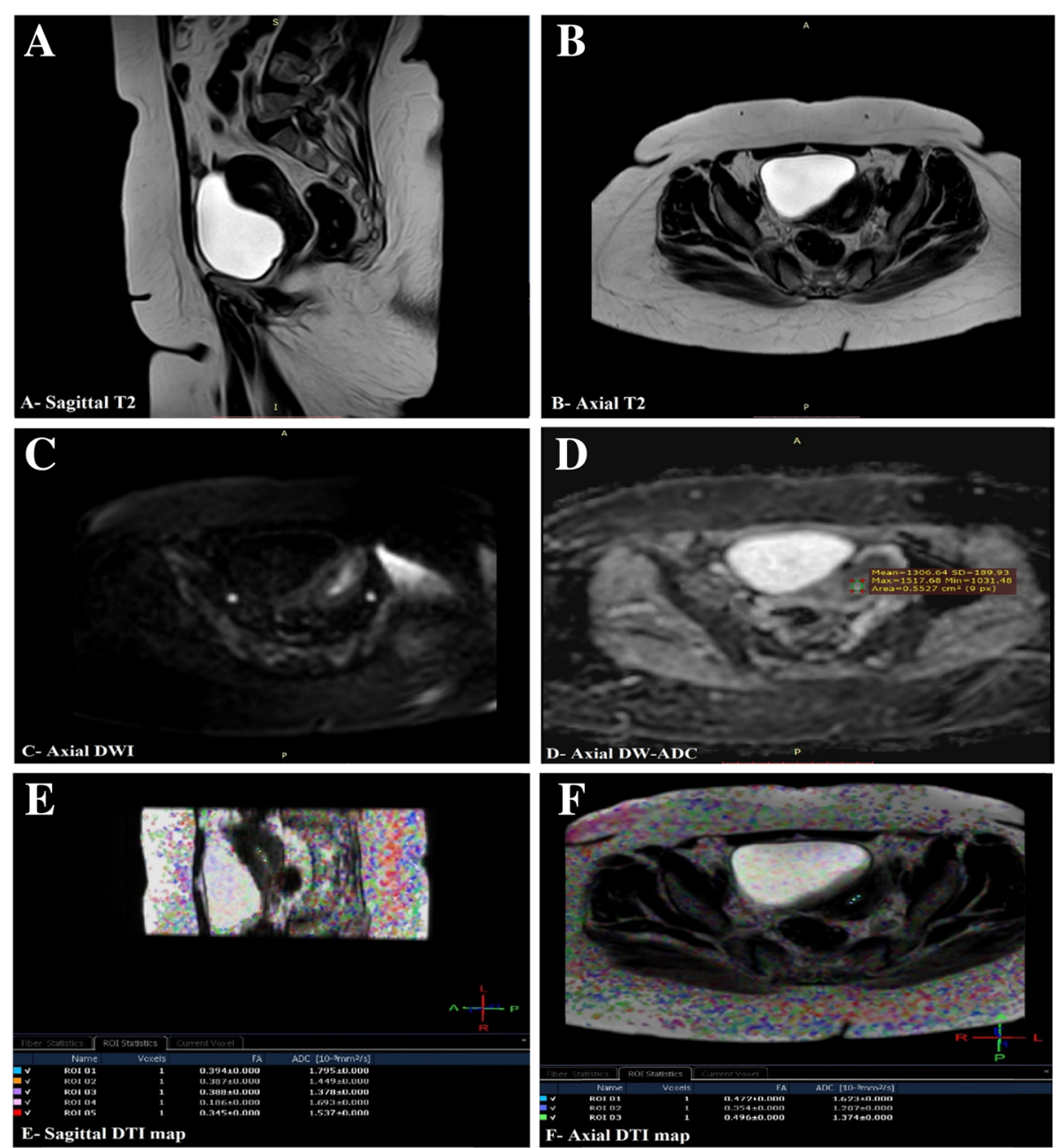

Fig. 2 A 55-year-old postmenopausal female with endometrial thickness $5 \mathrm{~mm}$ by TVS. a, b Sagittal and axial T2 Wls show normal zonal anatomy of the uterus. The central high signal stripe represents the endometrium (red arrows); the adjacent band of low signal intensity represents the junctional zone (yellow arrows). The outer myometrium is of intermediate SI (white arrows). c Axial DWI with b value of $1000 \mathrm{~s} / \mathrm{mm}^{2}$ shows normal appearance of the endometrium with high signal intensity (arrow). $\mathbf{d}$ Axial DW-ADC map image shows normal appearance of the endometrium with intermediate signal intensity. Mean DW-ADC value $=$ $1.306 \times 10^{-3} \mathrm{~mm}^{2} / \mathrm{s}$. e, f Sagittal and axial DT map images demonstrate values of DT-FA, and DT-ADC (MD) in multiple ROl along the endometrial stripe. Mean DT-FA value $=0.378$, and mean DT-ADC (MD) value $=1.51 \times 10^{-3} \mathrm{~mm}^{2} / \mathrm{s}$. Diagnosis: normal endometrium

For the ROC curve of DT-MD, the sensitivity, specificity, and accuracy at the cutoff point $\left(1.5065 \times 10^{-3}\right.$ $\mathrm{mm}^{2} / \mathrm{s}$ ) were $100.0 \%, 96.0 \%$, and $97.8 \%$ respectively (Table 4).

\section{For differentiation of normal and malignant endometrial} lesions

The ROC curve for DW-ADC: using the cutoff point $\left(1.190 \times 10^{-3} \mathrm{~mm}^{2} / \mathrm{s}\right)$, had sensitivity, specificity, and accuracy of $95.0 \%, 91.7 \%$, and $93.2 \%$ respectively (Table 4 ).

The ROC curve for DT-FA, at the cutoff point (0.3415), had relative lower sensitivity, specificity, and accuracy of $75.0 \%, 52.0 \%$, and $62.2 \%$ respectively (Table 4 ).
The ROC curve for $D T-M D$, the sensitivity, specificity, and accuracy at the cutoff point $\left(1.032 \times 10^{-3} \mathrm{~mm}^{2} / \mathrm{s}\right)$ were $95.0 \%, 100.0 \%$, and $97.6 \%$ respectively (Table 4 ).

\section{Discussion}

To the best of our knowledge, this study is the first to examine in vivo human endometrium in normal and different pathological conditions (benign and malignant) using DTI in addition to DWI.

In evaluation of endometrial thickness by TVS among the studied patients, differentiation between benign and malignant endometrial lesions is not possible depending on measuring the endometrial thickness only. This correlates with Singh and his colleagues [11], who found 

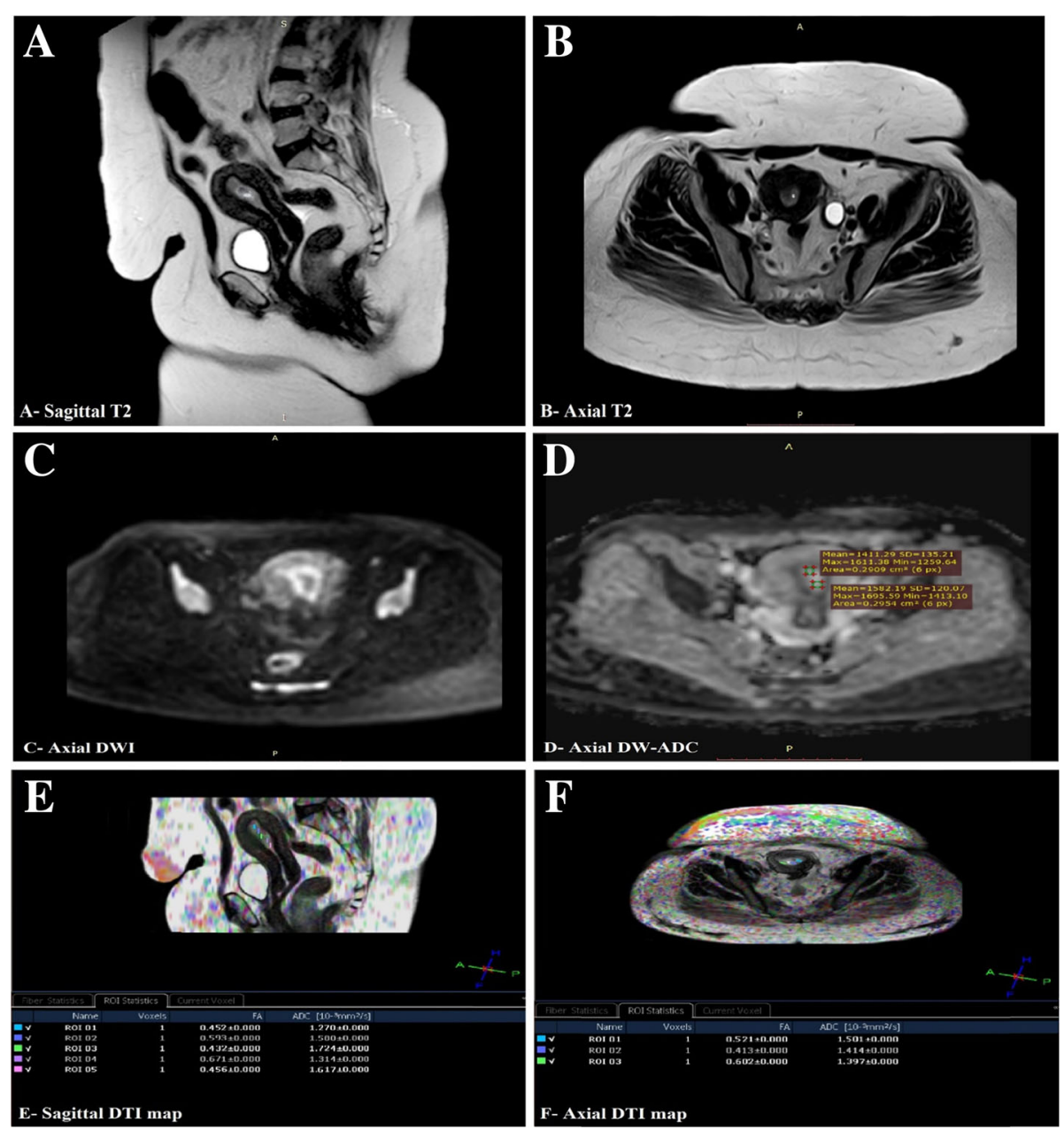

Fig. 3 A 54-year-old postmenopausal female presented by abnormal vaginal bleeding. On TVS examination, there was a large echogenic lesion in the endometrial cavity measuring about $12 \mathrm{~mm}$ in diameter with cystic changes inside. $\mathbf{a}$, b Sagittal and axial T2 Wls show endometrial thickening. The polyp appears of slightly low signal intensity compared with normal endometrium (red lines). There is a low signal intensity central fibrous core (blue arrows), and small high signal intensity intratumoral cyst (yellow arrows). c Axial DWI with b value of $1000 \mathrm{~s} / \mathrm{mm}^{2}$ shows high signal intensity of the thickened endometrium. The polyp appears of intermediate SI lower than that of the endometrium (red arrow). $\mathbf{d}$ Axial DW-ADC map image shows thickened endometrium with intermediate signal intensity. Mean DW-ADC value $=1.511 \times 10^{-3} \mathrm{~mm}^{2} / \mathrm{s}$. e, f Sagittal, and axial DTI map images demonstrate endometrial polyp mean DT-FA value $=0.518$, and mean DT-MD value $=1.477 \times 10^{-3} \mathrm{~mm}^{2} / \mathrm{s}$. Diagnosis: pathologically proven endometrial polyp

that endometrial thickness could not be reliable for detecting patients at high risk of developing endometrial cancers.

In this study, evaluation of 24 patients with normal endometrium, the mean values of DT-FA and DT-MD were $0.349 \pm 0.08$ and $1.59 \pm 0.06\left[\times 10^{-3} \mathrm{~mm}^{2} / \mathrm{s}\right] \mathrm{re}-$ spectively. He and his colleagues [12] found that mean DT-FA values of normal endometrium ranged from 0.138 to 0.279 , and that of DT-MD ranged from 1.018 to $1.476\left[\times 10^{-3} \mathrm{~mm}^{2} / \mathrm{s}\right.$. Fujimoto and his colleagues [13] reported that mean DT-FA value of normal endometrium was $0.186 \pm 0.039$ and that of DT-MD was $0.97 \pm 0.10$ $\left[\times 10^{-3} \mathrm{~mm}^{2} / \mathrm{s}\right]$. Both studies' findings are slightly different from the results of the current study as we included both pre- and postmenopausal females
This study included 21 females with pathologically proven benign endometrial lesions, and there was no significant difference between DW-ADC values of different benign pathologies comparing to their histopathological results $(P$ value $=0.179)$. These results are in harmony with Elsammak and his colleagues [14] and Mansour and his colleagues [15], who stated that the difference of DW-ADC measurements among different benign endometrial lesions was not statistically significant.

There was a significant statistical difference between DT-FA and DT-MD values of different benign pathologies comparing to their histopathological results $(P$ value $=0.014$ and $<0.001$ ) respectively.

The existing study included 20 women with pathologically proven endometrial cancer. The mean value of 
Table 2 Number of pathology results of benign and malignant endometrial lesions and its mean values of DW-ADC, DT-FA, and DTADC (MD)

\begin{tabular}{|c|c|c|c|c|}
\hline Benign pathology & No. & Mean DW-ADC \pm SD & Mean DT-FA \pm SD & Mean DT-MD \pm SD \\
\hline Endometrial polyp & $\begin{array}{l}2 \\
(9.5 \%)\end{array}$ & $1.615 \pm 0.05233$ & $0.4595 \pm 0.07990$ & $1.4645 \pm 0.01768$ \\
\hline Sub-mucous fibroid & $\begin{array}{l}2 \\
(9.5 \%)\end{array}$ & $1.284 \pm 0.13011$ & $0.2665 \pm 0.01768$ & $1.4140 \pm 0.02121$ \\
\hline Endometrial adhesion & $\begin{array}{l}1 \\
(4.8 \%)\end{array}$ & $1.452 \pm 0.0$ & $0.3020 \pm 0.0$ & $1.4210 \pm 0.0$ \\
\hline Tamoxifen-induced hyperplasia & $\begin{array}{l}6 \\
(28.6 \%)\end{array}$ & $1.522 \pm 0.16364$ & $0.2878 \pm 0.04794$ & $1.4295 \pm 0.05386$ \\
\hline $\begin{array}{l}\text { Simple hyperplasia without } \\
\text { cellular atypia (cystic) }\end{array}$ & $\begin{array}{l}5 \\
(23.8 \%)\end{array}$ & $1.651 \pm 0.16233$ & $0.2242 \pm 0.09106$ & $1.3292 \pm 0.03167$ \\
\hline $\begin{array}{l}\text { Complex hyperplasia without cellular atypia } \\
\text { (adenomatous) }\end{array}$ & $\begin{array}{l}3 \\
(14.3 \%)\end{array}$ & $1.629 \pm 0.09531$ & $0.3490 \pm 0.02464$ & $1.2927 \pm 0.01531$ \\
\hline Atypical hyperplasia & $\begin{array}{l}2 \\
(9.5 \%)\end{array}$ & $1.645 \pm 0.22981$ & $0.2365 \pm 0.04596$ & $1.1945 \pm 0.01768$ \\
\hline Total & $\begin{array}{l}21 \\
100 \%\end{array}$ & $1.562 \pm 0.17016$ & $0.2915 \pm 0.08694$ & $1.3651 \pm 0.08747$ \\
\hline Test of significance & & $P 1=0.1799$ & $\mathrm{P} 1=0.014^{*}$ & $\mathrm{P} 1<0.001^{*}$ \\
\hline Malignant pathology & No. & Mean DW-ADC \pm SD & Mean DT-FA \pm SD & Mean DT-MD \pm SD \\
\hline Endometrioid adenocarcinoma G1 & $\begin{array}{l}8 \\
(40 \%)\end{array}$ & $0.9899 \pm 0.12611$ & $0.3441 \pm 0.05055$ & $0.9658 \pm 0.07447$ \\
\hline Endometrioid adenocarcinoma G2 & $\begin{array}{l}4 \\
(20 \%)\end{array}$ & $0.8635 \pm 0.06998$ & $0.2620 \pm 0.05373$ & $0.7460 \pm 0.08465$ \\
\hline Endometrioid adenocarcinoma G3 & $\begin{array}{l}2 \\
(10 \%)\end{array}$ & $0.6985 \pm 0.02758$ & $0.4060 \pm 0.10889$ & $0.4420 \pm 0.04667$ \\
\hline Papillary serous carcinoma & $\begin{array}{l}2 \\
(10 \%)\end{array}$ & $0.6275 \pm 0.05869$ & $0.2355 \pm 0.05586$ & $0.4635 \pm 0.00778$ \\
\hline $\begin{array}{l}\text { Mixed type adenocarcinoma (endometrioid } \\
\text { and serous) }\end{array}$ & $\begin{array}{l}2 \\
(10 \%)\end{array}$ & $0.7155 \pm 0.02051$ & $0.2385 \pm 0.06293$ & $0.4155 \pm 0.02051$ \\
\hline Clear cell carcinoma & $\begin{array}{l}1 \\
(5 \%)\end{array}$ & $0.897 \pm 0.0$ & $0.1480 \pm 0.0$ & $0.4970 \pm 0.0$ \\
\hline Endometrial stromal sarcoma & $\begin{array}{l}1 \\
(5 \%)\end{array}$ & $0.912 \pm 0.0$ & $0.2800 \pm 0.0$ & $0.4400 \pm 0.0$ \\
\hline Total & 20 & $0.8633 \pm 0.15753$ & $0.2994 \pm 0.08230$ & $0.7144 \pm 0.24580$ \\
\hline Test of significance & & $\mathrm{P} 2=0.0044^{*}$ & $P 2=0.018^{*}$ & $\mathrm{P} 2<0.001^{*}$ \\
\hline
\end{tabular}

P1: for differentiation between different benign lesions. P2: for differentiation between different malignant lesions

DW-ADC for malignant endometrial lesions was $0.86 \pm$ $0.16\left[\times 10^{-3} \mathrm{~mm}^{2} / \mathrm{s}\right]$. This is in harmony with Elsammak and his colleagues and Mansour and his colleagues [14, $15]$, who reported that DW-ADC mean value of malignant endometrial lesions was $0.82 \pm 1.09 \times 10^{-3} \mathrm{~mm}^{2} / \mathrm{s}$ and $0.95 \pm 0.24 \times 10^{-3} \mathrm{~mm}^{2} / \mathrm{s}$ respectively.

Concerning mean DTI parameters of all malignant endometrial lesions in this study, DT-FA $=0.299 \pm 0.08$ and DT-MD $=0.71 \pm 0.25\left[\times 10^{-3} \mathrm{~mm}^{2} / \mathrm{s}\right]$. These findings are similar to that of Yamada and his colleagues [16] whose results were mean DT-FA $=0.299 \pm 0.051$ and mean DT-MD $=0.836 \pm 0.117\left[\times 10^{-3} \mathrm{~mm}^{2} / \mathrm{s}\right]$, and also in harmony with Tian and his colleagues [17] whose results were mean DT-FA $=0.165 \pm 0.017$ and mean DT-MD $=1.04 \pm 0.12\left[\times 10^{-3} \mathrm{~mm}^{2} / \mathrm{s}\right]$.
DTI can quantify the direction of water diffusion. DTI parameters are known to reflect microstructural organization. The FA value reflects the degree to which the three eigen-values differ from one another and ranges from 0 (completely isotropic) to 1 (maximally anisotropic), it denotes the degree of anisotropy and leads to asynchronous changes in the three orthogonal eigenvectors in each pixel of DTI. The MD value describes the directionally averaged diffusion that resembles unrestricted diffusion of water protons. Barriers and various components in the tissues restrict water molecules free displacement and this explains lower MD in malignant endometrial lesions compared to benign and normal endometrium [18]. 

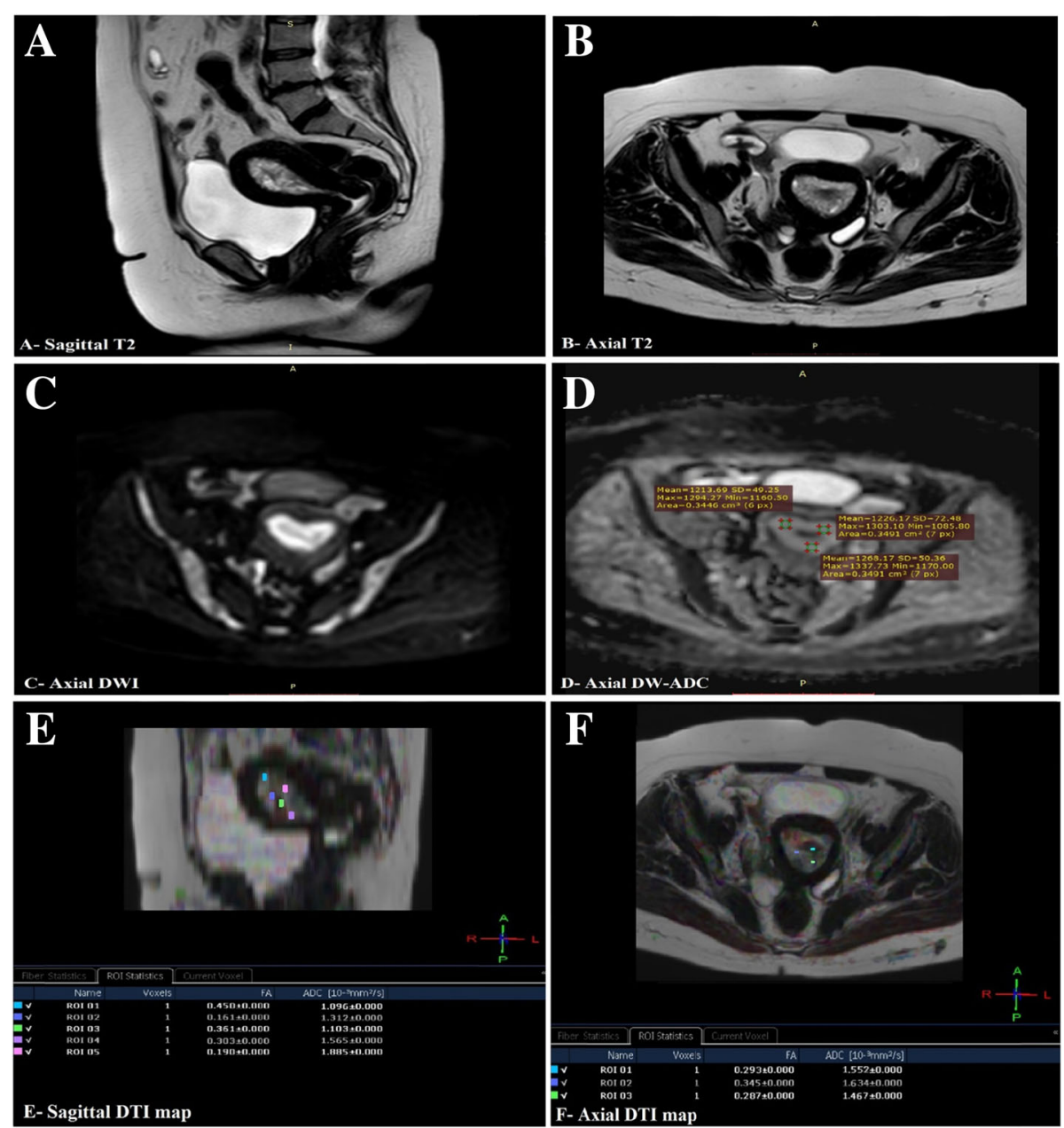

Fig. 4 A 45-year-old premenopausal female with history of breast cancer. The patient received tamoxifen therapy for 1 year. By TVS examination, the endometrium showed diffuse enlargement, measuring about $20 \mathrm{~mm}$ in diameter at the fundus with variable sized cystic changes inside. $\mathbf{a}, \mathbf{b}$ Sagittal and axial T2 Wls show enlarged endometrium with heterogeneous signal intensity (blue arrows) due to associated cystic changes, and prominent stromal proliferation. c Axial DWI with $b$ value of $1000 \mathrm{~s} / \mathrm{mm}^{2}$ shows high signal intensity of the thickened endometrium with central areas of intermediate SI (red arrow). d Axial DW-ADC map image shows thickened endometrium with intermediate signal intensity. Mean DWADC value $=1.232 \times 10^{-3} \mathrm{~mm}^{2} / \mathrm{s}$. e, f Sagittal and axial DTI map images demonstrate values of DT-FA and DT-MD in multiple ROI along the thickened endometrium. Mean DT-FA value $=0.299$, and mean DT-ADC (MD) value $=1.552 \times 10^{-3} \mathrm{~mm}^{2} / \mathrm{s}$. Diagnosis: Tamoxifen-induced endometrial hyperplasia

\section{In differentiation between normal and malignant groups in the current study}

(a) DW-ADC mean values: There was a significant statistical difference between normal and malignant group ( $P$ value $<0.001)$. Using DW-ADC value of $1.19 \times 10^{-3} \mathrm{~mm}^{2} / \mathrm{s}$ as the cutoff point in distinguishing normal endometrium from malignant endometrial lesions, the sensitivity, specificity, and accuracy were 95.0\%, 91.7\%, and 93.2\% respectively. This correlates with Tamai and his colleagues [19], who reported that mean DW-ADC value of endometrial cancer $\left(0.88 \pm 0.16 \times 10^{-3} \mathrm{~mm}^{2} / \mathrm{s}\right)$ was significantly lower than that of normal endometrium $\left(1.53 \pm 0.10 \times 10^{-3} \mathrm{~mm}^{2} / \mathrm{s}\right)(P$ value $<0.01)$

(b) DT-FA mean values: There was a significant statistical difference between normal and malignant group ( $P$ value $=0.02)$. Using DT-FA value of 0.3415 as the cutoff point in distinguishing normal endometrium from endometrial malignancies, the sensitivity, specificity, and accuracy were $75.0 \%$, $52.0 \%$, and $62.2 \%$ respectively. This is slightly differs from the results obtained by Yamada and his colleagues [16], who reported that on DT-FA maps, 

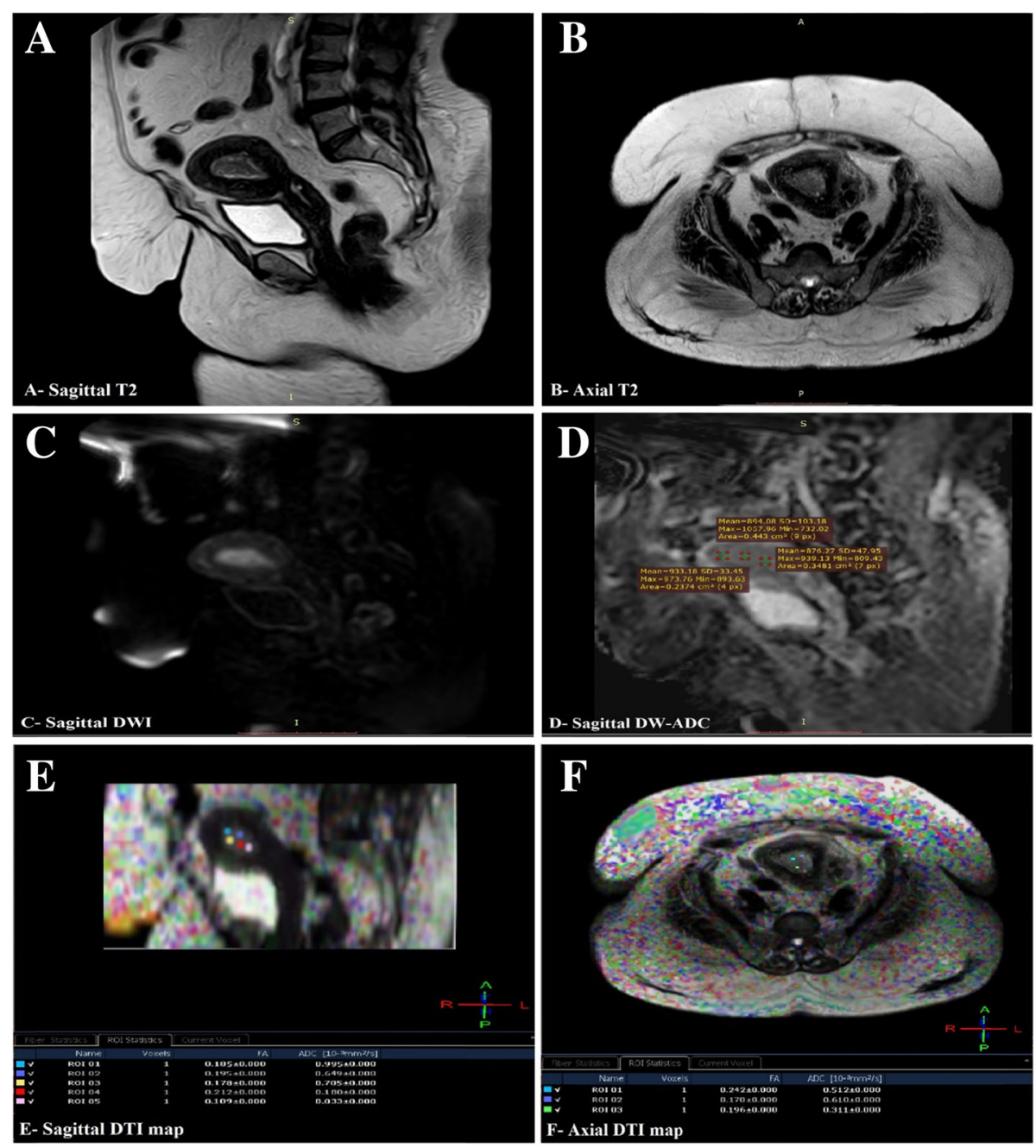

Fig. 5 A 59-year-old postmenopausal female presented by abnormal vaginal bleeding. On TVS examination, the endometrium was thick and echogenic measuring about $19 \mathrm{~mm}$ in diameter with relatively well-defined margins. a, b Sagittal and axial T2 Wls show irregular endometrial thickening which is occupied by a soft-tissue mass displaying intermediate SI (red stars). No visible tumor breaching through the junctional zone. No myometrial invasion or cervical extension. c Sagittal DWI with $b$ value of $1000 \mathrm{~s} / \mathrm{mm}^{2}$ shows high signal intensity of the endometrial softtissue mass. $\mathbf{d}$ Sagittal DW-ADC map image shows low signal intensity of the endometrial soft-tissue mass. Mean DW-ADC value $=0.901 \times 10^{-3}$ $\mathrm{mm}^{2} / \mathrm{s}$. e, f Sagittal and axial DTI map images demonstrate values of DT-FA and DT-MD in multiple ROI along the endometrial mass. Mean DT-FA value $=0.186$, and mean DT-MD value $=0.499 \times 10^{-3} \mathrm{~mm}^{2} / \mathrm{s}$. Diagnosis: pathologically proved endometrioid adenocarcinoma $\mathrm{G} 2$

Table 3 Mean values of DWI-ADC and DTI-FA and MD of different studied groups

\begin{tabular}{|c|c|c|c|c|c|}
\hline & $\begin{array}{l}\text { Normal } \\
\text { No. }=24\end{array}$ & $\begin{array}{l}\text { Benign } \\
\text { No. }=21\end{array}$ & $\begin{array}{l}\text { Malignant } \\
\text { No. }=20\end{array}$ & Test of significance & Within-group comparison \\
\hline $\begin{array}{l}\text { DWI-ADC } \\
{\left[\times 10^{-3} \mathrm{~mm}^{2} / \mathrm{s}\right]}\end{array}$ & $1.43 \pm 0.13$ & $1.56 \pm 0.17$ & $0.86 \pm 0.16$ & $\begin{array}{l}F=120.52 \\
P<0.001^{*}\end{array}$ & $\begin{array}{l}\mathrm{P} 1=0.006^{*} \\
\mathrm{P} 2<0.001^{*} \\
\mathrm{P} 3<0.001^{*}\end{array}$ \\
\hline DTI-FA & $0.349 \pm 0.08$ & $0.29 \pm 0.09$ & $0.299 \pm 0.08$ & $\begin{array}{l}F=3.26 \\
P=0.04^{*}\end{array}$ & $\begin{array}{l}\mathrm{P} 1=0.02^{*} \\
\mathrm{P} 2=0.052 \\
\mathrm{P} 3=0.76\end{array}$ \\
\hline $\begin{array}{l}\text { DTI-ADC (MD) } \\
{\left[\times 10^{-3} \mathrm{~mm}^{2} / \mathrm{s}\right]}\end{array}$ & $1.59 \pm 0.06$ & $1.37 \pm 0.09$ & $0.71 \pm 0.25$ & $\begin{array}{l}F=200.05 \\
P<0.001^{*}\end{array}$ & $\begin{array}{l}\mathrm{P} 1<0.001^{*} \\
\mathrm{P} 2<0.001^{*} \\
\mathrm{P} 3<0.001^{*}\end{array}$ \\
\hline
\end{tabular}

F: one-way ANOVA test. P1: the difference between normal and benign lesions. P2: the difference between normal and malignant lesions. P3: the difference between benign and malignant lesions 

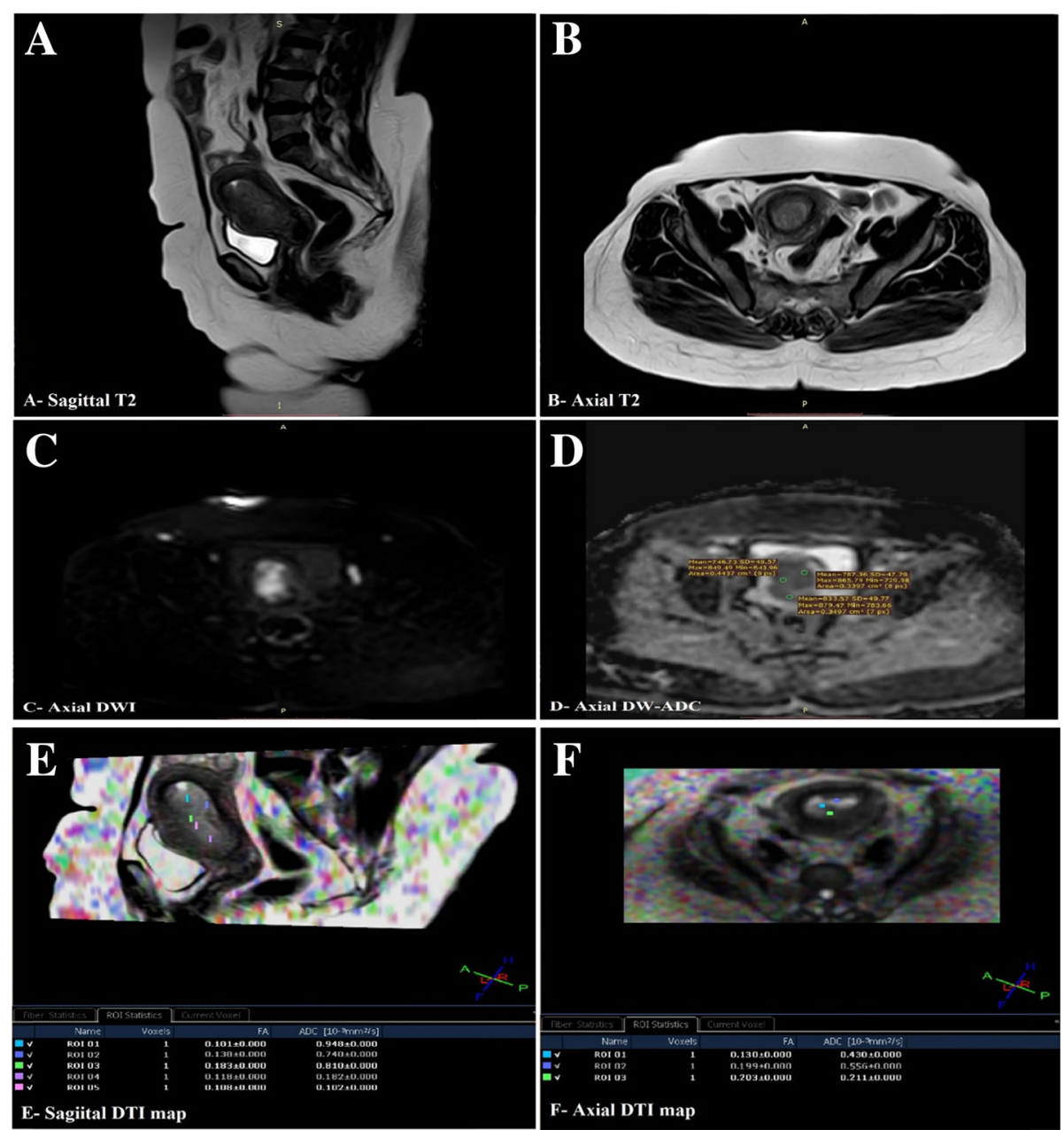

Fig. 6 A 56-year-old postmenopausal female presented by abnormal vaginal bleeding. On TVS examination, there was an ill-defined endometrial polypoid soft-tissue mass of heterogeneous echogenicity measuring about $20 \mathrm{~mm}$ in maximum diameter. $\mathbf{a}, \mathbf{b}$ Sagittal and axial T2 WIs show irregular endometrial soft-tissue mass with ill-defined margins displaying intermediate SI (red stars), distending, and filling the endometrial cavity with poor tumor-to-myometrium interface (blue arrows). The mass also extends to the cervix (yellow arrow). c Axial DWI with b value of 1000 s/ $\mathrm{mm}^{2}$ shows high $\mathrm{SI}$ of the endometrial soft-tissue mass. $\mathbf{d}$ Axial DW-ADC map image shows low signal intensity of the endometrial soft-tissue mass. Mean DW-ADC value of the mass $=0.789 \times 10^{-3} \mathrm{~mm}^{2} / \mathrm{s}$. e, $\mathbf{f}$ Sagittal and axial DTI map images demonstrate values of DT-FA and DT-MD in multiple ROI. Mean DT-FA and DT-MD values of the endometrial mass $=0.148$ and $0.497 \times 10^{-3} \mathrm{~mm}^{2} / \mathrm{s}$ respectively. Diagnosis: pathologically proved endometrial clear cell carcinoma

there were no significant differences in DT-FA mean values between endometrial carcinoma and normal endometrium $(P$ value $=0.325)$.

(c) DT-MD mean values: There was a significant statistical difference between normal and malignant group ( $P$ value $<0.001)$. Using DT-MD value of $1.032 \times 10^{-3} \mathrm{~mm}^{2} / \mathrm{s}$ as the cutoff point in distinguishing normal endometrium from malignant endometrial lesions, the sensitivity, specificity, and accuracy were $95.0 \%, 100.0 \%$, and $97.6 \%$ respectively. This agrees with Yamada and his colleagues [16], who stated that on DT-ADC (MD) maps, carcinoma had significantly lower DT-MD values (mean $=0.836 \pm 0.117)$ than normal endometrium $($ mean $=1.75 \pm 0.337)(P$ value $<0.001)$.

\section{In differentiation between normal and benign groups in this study}

(a) DW-ADC mean values: There was a significant statistical difference between normal and benign group $(P$ value $=0.006)$. Using DW-ADC value of $1.495 \times 10^{-3} \mathrm{~mm}^{2} / \mathrm{s}$ as the cutoff point in distinguishing normal endometrium from benign endometrial diseases, the sensitivity, specificity, and accuracy were $61.9 \%, 58.3 \%$, and $60.0 \%$ respectively. 
Table 4 The validity of DW-ADC, DT-FA, and DT-MD in differentiation of normal, benign, and malignant endometrium

\begin{tabular}{|c|c|c|c|c|c|c|c|c|}
\hline & AUC $(95 \% \mathrm{Cl})$ & $P$ value & Cutoff point & Sensitivity (\%) & Specificity (\%) & PPV (\%) & NPV (\%) & Accuracy (\%) \\
\hline \multicolumn{9}{|c|}{ Differentiating benign and malignant endometrial lesions } \\
\hline DW-ADC & $1.0(1.0-1.0)$ & $<0.001^{*}$ & 1.21 & 89.5 & 95.5 & 94.4 & 91.3 & 92.7 \\
\hline DT-FA & $0.47(0.29-0.65)$ & 0.09 & 0.294 & 55.0 & 52.4 & 52.4 & 55.0 & 53.7 \\
\hline DT-MD & $1.0(1.0-1.0)$ & $<0.001^{*}$ & 1.03 & 95.0 & 100.0 & 100.0 & 95.5 & 97.6 \\
\hline \multicolumn{9}{|c|}{ Differentiating normal and benign endometrial lesions } \\
\hline DW-ADC & $1.0(1.0-1.0)$ & $0.006^{*}$ & 1.495 & 61.9 & 58.3 & 56.5 & 63.6 & 60.0 \\
\hline DT-FA & $0.70(0.55-0.85)$ & $0.02^{*}$ & 0.342 & 76.2 & 52.0 & 53.3 & 68.8 & 58.7 \\
\hline DT-MD & $1.0(1.0-1.0)$ & $<0.001^{*}$ & 1.5065 & 100.0 & 96.0 & 95.5 & 100.0 & 97.8 \\
\hline \multicolumn{9}{|c|}{ Differentiating normal and malignant endometrial lesions } \\
\hline DW-ADC & $1.0(1.0-1.0)$ & $<0.001^{*}$ & 1.190 & 95.0 & 91.7 & 90.5 & 95.0 & 93.2 \\
\hline DT-FA & $\begin{array}{l}0.69 \\
(0.54-0.85)\end{array}$ & $0.02^{*}$ & 0.3415 & 75.0 & 52.0 & 52.0 & 72.0 & 62.2 \\
\hline DT-MD & $1.0(1.0-1.0)$ & $<0.001^{*}$ & 1.032 & 95.0 & 100.0 & 100.0 & 95.5 & 97.6 \\
\hline
\end{tabular}

(b) DT-FA mean values: There was a significant statistical difference between normal and benign group $(P$ value $=0.02)$. Using DT-FA value of 0.342 as the cutoff point in distinguishing normal endometrium from benign endometrial diseases, the sensitivity, specificity, and accuracy were $76.2 \%, 52.0 \%$, and $58.7 \%$, respectively.

(c) DT-MD mean values: There was a significant statistical difference between normal and benign group ( $P$ value $<0.001$ ). Using DT-MD value of $1.51 \times 10^{-3} \mathrm{~mm}^{2} / \mathrm{s}$ as the cutoff point in distinguishing normal endometrium from benign endometrial diseases, the sensitivity, specificity, and accuracy were $100.0 \%, 96.0 \%$, and $97.8 \%$ respectively.

\section{In differentiation between benign and malignant groups in the present study}

(a) DW-ADC mean values: There was a significant statistical difference between benign and malignant group ( $P$ value $<0.001$ ). Using DW-ADC value of $1.21 \times 10^{-3} \mathrm{~mm}^{2} / \mathrm{s}$ as the cutoff point in distinguishing benign from malignant endometrial lesions, the sensitivity, specificity, and accuracy were $89.5 \%, 95.5 \%$, and $92.7 \%$ respectively. This is harmonious with Mansour and his colleagues [15], who found a significant difference between the mean DW-ADC values of malignant endometrial masses $\left(0.95 \pm 0.24 \times 10^{-3} \mathrm{~mm}^{2} / \mathrm{s}\right)$ and benign lesions $\left(1.52 \pm 0.25 \times 10^{-3} \mathrm{~mm}^{2} / \mathrm{s}\right)(P$ value $<0.001)$ and reported that DW-ADC measurements at high $b$ value $(b=1000)$ could achieve $95.45 \%$ sensitivity, $92.86 \%$ specificity, and $94 \%$ accuracy, in diagnosis of benign and malignant endometrial lesions. Elsammak and his colleagues and Karakas and his colleagues $[14,20]$ reported that using DW-ADC value of $1.19 \times 10^{-3} \mathrm{~mm} 2 / \mathrm{s}$ and $0.908 \times 10^{-3} \mathrm{~mm}^{2} / \mathrm{s}$ respectively as a cutoff point had up to $88.9 \%$ sensitivity, $100 \%$ specificity, and $93 \%$ accuracy in distinguishing benign from malignant endometrial lesions.

(b) DT-FA mean values: There was no significant difference between benign and malignant group $(P$ value $=0.09$ ).

(c) DT-MD mean values: There was a significant statistical difference between benign and malignant group ( $P$ value $<0.001$ ). Using DT-MD value of $1.03\left[\times 10^{-3} \mathrm{~mm}^{2} / \mathrm{s}\right]$ as the cutoff point in distinguishing benign from malignant endometrial lesions, the sensitivity, specificity, and accuracy were $95.0 \%, 100.0 \%$, and $97.6 \%$ respectively.

To the best of our knowledge, this is first study used DTI parameters for evaluation of different benign endometrial lesions, differentiation between normal and benign endometrial lesions and differentiation between benign and malignant endometrial pathologies. So, unfortunately, the study results regarding benign lesions could not be compared with other studies using DT-FA and DT-MD.

This study results revealed that DT-MD had a higher sensitivity, specificity, and accuracy than both DW-ADC, and DT-FA in differentiating normal, benign, and malignant endometrial pathologies even in early stages. This can cope with Yamada and his colleagues [16] who found that there were no significant differences in FA values between endometrial carcinoma and normal endometrium $(P=0.325)$. On MD maps, endometrial carcinoma had significantly lower MD values than normal endometrium $(P<0.001)$. However, their results demonstrated that AUC for FA 
values was the largest among all DTI parameters for differentiating Grade 2 or 3 from Grade 1 and for differentiating Grade 3 from Grade1 or 2 endometrial carcinoma. Thus, their data validated the use of DTI parameters, particularly FA values, for assessing the aggressiveness of endometrial carcinoma.

Also, Yamaguchi et al [21] concluded that FA values tended to decrease with the increasing grade of malignancy, a tendency that may be due to intratumoral heterogeneity and higher cellular density.

So, we can conclude that DT-MD is more useful in differentiation of normal, benign, and malignant endometrium, while DT-FA is more applicable in grading of endometrial tumor and in degree of myometrial invasion (which is in need for future investigation).

\section{Limitations}

\section{Small number of cases}

Examining both premenopausal and postmenopausal women and including both normal and pathological (benign and malignant) endometrium, however, this is a preliminary study and we think it is more beneficial in the future to be focused on 2 main pathologies only.

\section{Conclusion}

From this study, we concluded that DTI is a valuable promising non-invasive tool that can be easily added to DWI, and conventional MRI techniques in assessment of human endometrium in vivo in different conditions either normal or pathological, and it has the ability to give more detailed information about different pathologies, and to increase the sensitivity, specificity, and accuracy in differentiating normal, benign, and malignant conditions, and thus help early management and decrease the possibility of misdiagnosis.

\section{Recommendations}

- Both DWI and DTI are important complementary and supplementary tools to conventional MRI, not replacing, and thus they should be done as routine image modality side by side to conventional imaging for endometrial assessment.

- Further studies with larger number of cases are needed to give more reliable quantitative and qualitative data. Further studies for use of DTI parameters in myometrial invasion and grading of endometrial carcinoma are needed.

\footnotetext{
Abbreviations

TVS: Transvaginal ultrasonography; MRI: Magnetic resonance imaging; EC: Endometrial cancer; DWI: Diffusion-weighted imaging; DTI: Diffusion tensor imaging; FA: Fractional anisotropy; MD: Mean diffusivity; FOV: Field of view; TR: Repetition time; TE: Echo time; SPIR: Selective partial inversion recovery; STIR: Short T1 inversion recovery; ADC: Apparent diffusion coefficient; SENSE : Sensitivity encoding sequence; EPI: Echo-planar imaging;
}

2D: Two dimension; ROI: Region of interest; SD: Standard deviation; PPV: Positive predictive value; NPV: Negative predictive value; DWADC: Diffusion-weighted-apparent diffusion coefficient; DT-MD: Diffusion tensor-mean diffusivity; DT-FA: Diffusion tensor-fractional anisotropy

\section{Acknowledgements}

To technicians in our institution who help in examination of patients.

\section{Authors' contributions}

M.A.L.: idea of the research, writing of the manuscript of the research, final revision of data and radiological images, and finalization of the research manuscript. M.S.T.: supervision of the radiological examination and revision of the radiological images and data. H.S.M.: collecting of the data, radiological examination of patients (under supervision), and helping in writing of the manuscript. All authors read and approved the final manuscript.

\section{Funding}

Not applicable (no funding).

\section{Availability of data and materials}

Authors can confirm that all relevant data are included in the article and/or its supplementary information files.

\section{Declarations}

Ethics approval and consent to participate

This study was approved by Mansoura Faculty of Medicine - Institutional Research Board (MFM-IRB), and written informed consent to participate was obtained from all patients. Ethics committee reference number of acceptance is MS.18.04.100.

Consent for publication

Informed consent was taken from enrolled patients for publication.

\section{Competing interests}

Not applicable. "The authors declare that they have no competing interests."

Received: 17 November 2020 Accepted: 4 April 2021

Published online: 15 April 2021

\section{References}

1. Bakir B, Sanli S, Bakir VL, Ayas S, Yildiz SO, lyibozkurt AC, Yavuz E (2017) Role of diffusion weighted MRI in the differential diagnosis of endometrial cancer, polyp, hyperplasia, and physiological thickening. Clin Imaging 41: 86-94. https://doi.org/10.1016/j.clinimag.2016.10.016

2. Kierans AS, Bennett GL, Haghighi M, Rosenkrantz AB (2014) Utility of conventional and diffusion-weighted MRI features in distinguishing benign from malignant endometrial lesions. Eur J Radiol 83(4):726-732. https://doi. org/10.1016/j.ejrad.2013.11.030

3. Wang X, Zhao Y, Hu Y, Zhou Y, Ye X, Liu K, Wang J (2017) Evaluation and validation of the diagnostic value of the apparent diffusion coefficient for differentiating early-stage endometrial carcinomas from benign mimickers at T MRI. Oncotarget 8(28):46390

4. Lee JH, Dighe MK, Dubinsky TJ (2012) Postmenopausal endometrial bleeding. Ultrasound Clin 7:23-32

5. Takeuchi M, Matsuzaki K, Uehara H, Yoshida S, Nishitani H, Shimazu H (2005) Pathologies of the uterine endometrial cavity: usual and unusual manifestations and pitfalls on magnetic resonance imaging. Eur Radiol 15(11):2244-2255. https://doi.org/10.1007/s00330-005-2814-x

6. Bozkurt DK, Bozkurt M, Nazli MA, Mutlu IN, Kilickesmez O (2015) Diffusionweighted and diffusion-tensor imaging of normal and diseased uterus. World J Radiol 7(7):149-156. https://doi.org/10.4329/wjr.v7.i7.149

7. Nougaret S, Addley H, Horta M, Cunha TM, Sala E (2018) Added value of diffusion-weighted imaging in endometrial cancer. In: Diffusion weighted imaging of the genitourinary system. Springer, Cham, pp 147-166

8. Nougaret S, Tirumani SH, Addley H, Pandey H, Sala E, Reinhold C (2013) Pearls and pitfalls in MRI of gynecologic malignancy with diffusionweighted technique. Am J Roentgenol 200(2):261-276. https://doi.org/1 $0.2214 /$ AJR.12.9713 
9. Toba M, Miyasaka N, Sakurai U, Yamada I, Eishi Y, Kubota T (2011) Diagnostic possibility of diffusion tensor imaging for the evaluation of myometrial invasion in endometrial cancer: an ex vivo study. J Magn Reson Imaging 34(3):616-622. https://doi.org/10.1002/jmri.22693

10. Taouli B (2010) Extra-cranial applications of diffusion-weighted MRI. Cambridge University Press. https://doi.org/10.1017/CBO9780511778070

11. Singh P, Dwivedi P, Mendiratta S (2016) Correlation of endometrial thickness with the histopathological pattern of endometrium in postmenopausal bleeding. J Obstetr Gynecol India 66(1):42-46. https://doi.org/10.1007/ s13224-014-0627-Z

12. He Y, Ding N, Li Y, Li Z, Xiang Y, Jin Z, Xue H (2015) 3-T diffusion tensor imaging (DTI) of normal uterus in young and middle aged females during the menstrual cycle: evaluation of the cyclic changes of fractional anisotropy (FA) and apparent diffusion coefficient (ADC) values. $\mathrm{Br} J$ Radio 88(1049):20150043. https://doi.org/10.1259/bjr.20150043

13. Fujimoto K, Kido A, Okada T, Uchikoshi M, Togashi K (2013) Diffusion tensor imaging (DTI) of the normal human uterus in vivo at 3 tesla: comparison of DTI parameters in the different uterine layers. J MagnReson Imaging 38(6): 1494-1500. https://doi.org/10.1002/jmri.24114

14. Elsammak A, Shehata S, Abulezz M, Gouhar G (2017) Efficiency of diffusion weighted magnetic resonance in differentiation between benign and malignant endometrial lesions. Egypt J Radiol Nuclear Med 48(3):751-759. https://doi.org/10.1016/j.ejrnm.2017.02.008

15. Mansour TMM, Ahmed YAA, Ahmed GAER (2019) The usefulness of diffusion-weighted MRI in the differentiation between focal uterine endometrial soft tissue lesions. Egypt J RadiolNucl Med 50:102

16. Yamada I, Wakana K, Kobayashi D, Miyasaka N, Oshima N, Wakabayashi A, Eishi Y (2019) Endometrial carcinoma: evaluation using diffusion tensor imaging and its correlation with histopathologic findings. J Magn Reson Imaging 50(1):250-260. https://doi.org/10.1002/jmri.26558

17. Tian S, Liu A, Zhu W, Li Y, Chen L, Chen A, Wei Q (2017) Difference in diffusion-weighted magnetic resonance imaging and diffusion tensor imaging parameters between endometrioid endometrial adenocarcinoma and uterine serous adenocarcinoma. Int J Gynecol Cancer 27(8):1708-1713. https://doi.org/10.1097/IGC.0000000000001054

18. Le Bihan D, Mangin JF, Poupon C et al (2001) Diffusion tensor imaging: concepts and applications. J Magn Reson Imaging 13(4):534-546. https:// doi.org/10.1002/jmri.1076

19. Tamai K, Koyama T, Saga T, Umeoka S, Mikami Y, Fujii S, Togashi K (2007) Diffusion weighted MR imaging of uterine endometrial cancer. J Magnetic Reson Imaging 26(3):682-687. https://doi.org/10.1002/jmri.20997

20. Karakas O, Karakas E, Dogan F, Kilicaslan N, Camuzcuoglu A, Incebiyik A, Camuzcuoglu H (2015) Diffusion-weighted MRI in the differential diagnosis of uterine endometrial cavity tumors. WienerklinischeWochenschrift 127(78):266-273

21. Yamaguchi K, Nakazono T, Egashira R, Komori Y, Nakamura J, Noguchi T, Irie $H$ (2017) Diagnostic performance of diffusion tensor imaging with readoutsegmented echo-planar imaging for invasive breast cancer: correlation of ADC and FA with pathological prognostic markers. Magn Reson Med Sci 16(3):245-252. https://doi.org/10.2463/mrms.mp.2016-0037

\section{Publisher's Note}

Springer Nature remains neutral with regard to jurisdictional claims in published maps and institutional affiliations.

\section{Submit your manuscript to a SpringerOpen ${ }^{\circ}$ journal and benefit from:}

- Convenient online submission

- Rigorous peer review

- Open access: articles freely available online

- High visibility within the field

- Retaining the copyright to your article

Submit your next manuscript at $>$ springeropen.com 